\title{
Phenotypic plasticity and longevity in plants and animals: cause and effect?
}

\author{
RENEE M BORGES \\ Centre for Ecological Sciences, Indian Institute of Science, Bangalore 560 012, India
}

(Email,renee@ces.iisc.ernet.in)

\begin{abstract}
Immobile plants and immobile modular animals outlive unitary animals. This paper discusses competing but not necessarily mutually exclusive theories to explain this extreme longevity, especially from the perspective of phenotypic plasticity. Stem cell immortality, vascular autonomy, and epicormic branching are some important features of the phenotypic plasticity of plants that contribute to their longevity. Monocarpy versus polycarpy can also influence the kind of senescent processes experienced by plants. How density-dependent phenomena affecting the establishment of juveniles in these immobile organisms can influence the evolution of senescence, and consequently longevity, is reviewed and discussed. Whether climate change scenarios will favour long-lived or short-lived organisms, with their attendant levels of plasticity, is also presented.
\end{abstract}

[Borges R M 2009 Phenotypic plasticity and longevity in plants and animals: cause and effect?; J. Biosci. 34 605-611]

\section{Introduction}

In the Amazon forests millennium-old trees exist (Chambers et al. 1998) that may occur with a density of one millenarian in every 200 hectares (Williamson et al. 1999). Elsewhere, living conifer trees have been dated to more than 4000 years with the longevity record for individual trees being held by the bristlecone pine Pinus longaeva living to 4713 (Lanner and Connor 2001) and 4770 (Flanary and Kletetschka 2005) years. On the other hand, the exclusively asexual triploid clonal shrub Lomatia tasmanica (Proteaceae) has been dated to 43,600 years (Lynch et al. 1998) with each individual ramet in the clone probably living for about 300 years. The largest living vertebrates, i.e. whales, are known to live to 211 years (Partridge and Gems 2002), and Galapagos tortoises close to that age (Powell and Caccone 2006). Thus some plants are certainly orders of magnitude more long-lived than animals. Why should this be so? What are the evolutionary explanations for longevity in general and for exceptional longevity in particular? Does longevity necessitate phenotypic plasticity or does plasticity confer longevity, especially in plants? This question was posed by Borges (2008) and is discussed further in the present paper.
Longevity is modulated by the processes of ageing and senescence. However, are ageing and senescence the same phenomena? Some authors use the term interchangeably (Monaghan et al. 2008; Ricklefs 2008), while others prefer to distinguish between the two (Munné-Bosch 2008). For example, Noodén and Leopold (1988) defined senescence as a well-regulated process that culminated in death, while ageing was considered a passive process, without endogenous regulation. From the perspective of a plant, leaf senescence that occurs annually, especially in deciduous plants, is a well-regulated process. However, plant evolutionary biologists such as Charlesworth (1980) consider senescence to be the reduction in age-specific survival and fecundity with advancing age. There are several evolutionary explanations for senescence which are an amalgam of the two views presented above. According to Haldane (1941) and Medawar (1952), while mortality from predation or disease may be unconnected to senescence, since individuals experience a decline in reproduction with age, therefore the selection pressure on individuals to ward off senescence should also decline with age. In the theory of antagonistic pleiotropy, Williams (1957) proposed that any mutations that may be detrimental at older ages are likely to

Keywords. Antagonistic pleiotropy; epicormic branching; free radical theory of ageing; monocarpy; polycarpy; senescence; telomere shortening 
be ignored by natural selection if they increased the fitness of younger age classes; consequently, natural selection should be blind to the effects of those mutations that cause physical declines after the reproductive period is over since they have no impact on individual fitness. Senescence in age-structured populations can thus be modified depending on tradeoffs between fecundity and survival at different ages (Kirkwood and Austad 2000). According to this view, in safe environments, where the risk of mortality from extrinsic factors is low, ageing will be retarded, while it will be accelerated in environments that have more external hazards (Kirkwood and Austad 2000). Thus, for example, those adaptations that may help to reduce mortality from extrinsic factors, such as wings (which enable escape from predators in birds and bats) or shells (which in giant tortoises can deny access to predators), should help to exert positive selection pressures to retard ageing resulting in greater longevity. This is found to be true for birds, bats, and tortoises which have higher than expected longevity compared to other related taxa. In the disposable soma theory of Kirkwood $(1977,2005)$, every individual experiences a trade-off between resource allocation to self-maintenance, i.e. repairing of cellular damage, and to reproductive success. Senescence in this theory is an outcome of the balance between these allocations. While all these theories provide a framework for the evolution or maintenance of senescence, they still do not provide explanations for why plants and animals differ so greatly in longevity, and why even among plants and animals there are great differences in patterns of senescence leading to differences in longevity. These can probably only be understood by combining life history theory with phenotypic responses to environmental (internal and external) variability and stresses.

\section{Proximal theories for senescence: differences between plants and animals?}

Borges (2008) emphasised the fact that a comparison between plants and animals should more profitably be replaced by a comparison between modular and unitary organisms, since modular plants and modular animals such as cnidaria share many features such as immobility, and also exhibit relatively greater longevity compared to unitary animals. A lack of senescence has been noted, for example, in the clonal cnidarian Hydra (Martínez 1998). Therefore, ensuing comparisons in this paper will be made between plants and modular animals on the one hand and unitary animals on the other, wherever possible. It is important, however, to note that while individual modular elements of some cnidarian colonies may ultimately senesce, the colony as a whole, which is often derived from clonally-produced progeny by processes such as budding, may persist without senescence (Jackson and Coates 1986). The same may occur with plants, such that the present-day individual plant may actually consist of functional products of contemporary meristems, while older meristems have undergone the process of senescence. The time scales at which senescence or lack thereof is measured may also, therefore, be very important in a comparative framework.

\subsection{Free radical theory}

The generation of harmful free radicals and reactive oxygen species (ROS) by the normal processes of metabolism is believed to result in accumulated damage to cells (Harman 1956; Lu and Finkel 2008) contributing to their senescence. In accordance with this theory, organisms with lower metabolic rates might be considered to have lower rates of ROS production and consequently less damage leading to lower senescence and greater longevity. Since metabolic rates scale with body mass in animals (Kleiber 1961; Peters 1983) and even in plants (Niklas 1994), it is possible that the generally positive although non-linear relationship observed between body mass and longevity is mediated by metabolic rates. However, there are certainly outlier taxa, especially ectotherms such as chelonians and crocodilians, in which large body mass and longevity are positively related (de Magalhães et al. 2007), although perhaps not through metabolic rate. The relationship between metabolic rates, body size and longevity is not straightforward, since birds, which generally have higher metabolic rates than mammals, have greater longevity when compared to mammals of the same size (Rottenberg 2007a). This anomaly, among others, is postulated to be partly explained by the fatty acid composition of the cell membranes of the different taxa (Hulbert et al. 2007). According to this theory, species with low membrane polyunsaturation have lesser amounts of oxidative stress and damage to cellular molecules via lower peroxidative susceptibility of fatty acyl chains. Whether this would also apply to plants is not yet known. Even within taxa such as birds, the exceptional longevity of some groups such a songbirds is thought to be related to high rates of evolution of cytochrome $b$ that involve mutations which presumably reduce ROS production (Rottenberg 2007a, b). Within mammals, longer-lived species generally have fewer mitochondria in their liver cells, and shorter-lived species generally produce higher amounts of ROS from these mitochondria than longer-lived counterparts (reviewed in Passos et al. 2007). In plants also, oxidative stress and singlet oxygen generation have been found to be responsible for senescence in stressful conditions such as drought in which case the senescence is brought about by a loss of antioxidant defences in the chloroplasts (Munné-Bosch et al. 2001). Yet, whether the free radical theory alone can explain longevity is unclear. 


\subsection{Telomere shortening}

Animal somatic cells in culture have a finite number of doublings (Hayflick and Moorehead 1961) caused by declining activity of telomerase resulting in telomere shortening at each doubling event; telomerase activity remains high however in the germ line and in stem cells (Wright et al. 1996), and could thus contribute to the immortality of cell lines (Campisi 2001; Cosme-Blanco and Chang 2008). However, even within the mammals, there are differences, since shortening of telomeres and senescence appear to be unrelated in the mouse (Wright and Shay 2000), while high telomerase activity was found throughout the lifespan of the longest-lived birds and mammals (Haussmann et al. 2003). Consistent with this theory, samples of pine needles and roots of the long-lived bristlecone pine indicate that the longest-lived trees have the greatest telomere lengths compared to short-lived and medium-aged trees of the same species; this was matched with comparable telomerase activity (Flanary and Kletetschka 2005). Yet, the telomere attrition theory of longevity also suffers from the anomaly of exceptional taxa that do not fit the predictions.

\section{Proximal theories for immortality}

\subsection{Stem cells and immortality}

Stem cells confer on plants and animals the ability to generate new tissue types and to give rise to differentiated organs from undifferentiated cells. However, the contributions of plant stem cells to phenotypic plasticity and thus effectively to longevity is probably much greater than in animals, especially since plant stem cells themselves may not age (reviewed in Borges 2008). Earlier, animal stem cells were considered to be quiescent; however, it is now believed that animal stem cells, such as those in mice, may periodically undergo division (Bradford et al. 1997 ) and thus may shows signs of ageing which may also affect their self-renewal abilities (Liang and Van Zant 2008; Roobrouck et al. 2008). Whether plant stem cells age is still an open question. However, plants, unlike most animals, can even undergo somatic embryogenesis from a single somatic cell, an ability that they share with colonial sessile cnidaria (Borges 2008). In the most remarkable model cnidarian Hydra, epithelial cells of the budding hyroid are all conferred with stem cell status, while the interstitial cells are all multipotent; thus budding which is the most prevalent method of reproduction in Hydra can easily be achieved from the hydroid body, while germ line cells can also be readily produced (Bosch and David 1987; Bosch 2007). Mammalian epithelial cells on the other hand, e.g. in the small intestine, have a very small population of stem cells (Moore and Lemischka 2006). Therefore, the number of stem cells as well as the intrinsic stemness of the tissue, as also their plasticity and ageing properties, can contribute significantly to the longevity of cell lines and of the organs or modules associated with them.

\subsection{Epicormic branching in plants}

Epicormic branching, which is branching from preventitious and hitherto dormant buds on the trunk of woody trees, is believed to contribute significantly to plant longevity especially in many species of conifers and angiosperms (Ishii and Ford 2001; Lanner 2002; Nicolini et al. 2003). In 400 year-old Douglas fir (Pseudostuga) trees, for example, epicormic foliage production is the major type of foliage production at the stage when no further height increase is possible (Ishii and Ford 2001). Thus, by the activation of meristematic tissue in non-conventional locations such as tree trunks, in response to environmental variation in crucial growth-related parameters such as light and temperature, plants can exhibit a modified architecture and increase longevity. This phenomenon has also been seen in woody tropical plants in which there is an increase in epicormic branching with tree height (Nicolini et al. 2003). Since there may be physical constraints on maximum tree height (Becker et al. 2000; Enquist et al. 2007), plants may use epicormic branching to exploit local light environments and thus increase their competitive ability relative to their neighbours (Ford and Ishii 2001). The phenomenal ability of plants to use light sensors to detect the presence of neighbours and to employ corresponding neighbour-avoiding growth strategies has already been well documented (reviewed in Borges 2005, 2008). The resprouting ability of woody plants after extensive damage following fire or mechanical forces (Paciorek et al. 2000) can also make significant contributions to plant longevity.

\subsection{Vascular modularity}

Animals are usually characterised by a closed circulatory system. Therefore, vascular blockages in any part of the animal body may have serious consequences for the whole organism resulting in a reduction in longevity. In plants, however, although there are circulatory routes governed by the root-shoot axis as well as long-distance sources and sinks, their modular nature also allows for local circulatory loops to be set up within modules which may involve local sources and sinks (Orians 2005). This vascular autonomy allows for parts of the plant to remain functional while other portions may be severely damaged. Furthermore, the wounding response in plants can often result in vessel blocking via local synthesis of lignin and suberin (Hawkins and Boudet 1996) which then effectively shuts down 
certain vascular pathways allowing for rejuvenation of the undamaged parts from meristematic tissue if necessary. Following wounding, mesophyll cells can also differentiate into tracheary elements, and contribute to vascular repair (Fukuda 1994). Therefore, the vascular autonomy of plant modules is an important contributory factor to the longevity of plants (Lanner 2002) allowing plant portions to survive intact with physiological autonomy despite death and senescence in other parts.

This combination of stem cells and modularity in plants can facilitate the enhanced plasticity of plants and a greater longevity that results from renewed and rejuvenated tissues. Furthermore, most plants are genetic mosaics as a result of somatic mutations in meristematic tissue, chromatin remodelling, as well as inter-meristem competition and subsequent selection between meristems This genetic mosaicism can contribute significantly to continual adaptive selection within plants resulting in appropriate responses to environmental assaults and thus to longevity (Salomonson 1996; Borges 2008; Sedivy et al. 2008). While both plants and modular organisms have competent resistance mechanism against parasites and pathogens (Bosch 2008; Xiao et al. 2008), it is not clear whether these mechanisms per se confer any special survival advantages resulting in greater longevity compared to unitary animals (Mocchegiani et al. 2007). It is probably the continual selection between modules as well as stem cell proliferation that give plants and modular organisms a survival edge over other organisms.

\section{Density-dependence, plasticity and longevity}

A fundamental distinguishing property of most plants and modular animals is their immobility. This means that until their death, individual plants are rooted in the same place, while their asexually derived progeny may expand into nearby available space. The sexually or asexually derived progeny of parent plants and their neighbours need to find space in the already crowded terrestrial rhizosphere and to partition the above-ground available light in order to support their autotrophic and/or saprophytic lifestyle. This can make density-dependent factors extremely important in the evolution of life history parameters in plants. According to Seymour and Doncaster (2007) this type of density dependence, where juveniles need to wait until they can find the space to establish, can result in runaway selection for reduced senescence which may even cause the evolution of intrinsic immortality. This is because juvenile establishment can happen only after the mortality of existing plants. This ecological scenario can result in the evolution of indefinite generation lengths (Doncaster 2003). Therefore, the dormancy exhibited by many plants, especially perennials (Rohde and Bhalerao 2007), is an important means of coping both with environmental assaults and with the phenomenon of density-dependent constraints on establishment. Dormancy can occur at various stages of the plant, from the seed stage onwards, with seeds lying in wait within the seed bank for long, indeterminate periods of time for conditions suitable for germination and establishment (Brown and Venable 1986; Venable and Brown 1988). It is possible that if the dormancy of the seed is also factored into the longevity profile of individuals, then plants will be estimated to have much longer lives. It is therefore extremely interesting to note that density-dependent effects in immobile animals resulting in reduced senescence may also explain the extreme longevity of the immobile Quahog clam Arctica islandica in which individuals can live to 200 years (Finch and Austad 2001). Similar explanations can apply to the longevity of the immobile sea anemone Anthopleura xanthogrammica which has an estimated longevity of 150 years (Sebens 1983).

\section{What type of senescence occurs in plants?}

Despite the various plasticity measures that plants have evolved to cope with uncertain internal and external environments (reviewed in Borges 2005, 2008), plants do senesce (Watkinson 1992; Thomas 2003). Still, the type of senescence varies, depending on whether the plant is annual or perennial, and whether it is monocarpic (the equivalent of semelparous in animals) or polycarpic (the equivalent of iteroparous in animals) (Watkinson and White 1985; Munné-Bosch 2007, 2008). Some authors view senescence as programmed degeneration leading to death (Noodén et al. 1997); however, in this case it is important to delineate whether it is only a part or the whole plant that is undergoing this process. For example, leaves may undergo well-orchestrated processes of senescence in each annual cycle depending on photoperiod cues; in this case, the plant withdraws important nutrients from the senescing leaves which undergo characteristic degenerative processes. Roots, on the other hand, may show limited periodic senescence; however, this has not been investigated in any detail. Therefore, depending on whether the plant is monocarpic or perennial, the plant may experience differing types of senescence. Monocarpic plants can experience senescence at the cellular, tissue and whole-plant level, as in grasses such as bamboos wherein the whole plant undergoes mortality after flowering (Keeley and Bond 1999). This is analogous to the whole-body senescence of salmon which die after reproduction (Smith 2004). Perennial plants, on the other hand, may only experience senescence at the tissue or modular level, and probably not at the whole-plant level (Munné-Bosch 2008). In this context, it is important to note that monocarpic and perennial plants differ in the indeterminacy and totipotency of their meristems, with scarcely any totipotency in the former. This matches well with the idea that phenotypic plasticity and longevity are 
closely related. Yet, even within perennial plants there are differences with woody plants having longer lifespans than non-woody plants, and individuals of non-clonal species living for much longer than ramets of clonal species (Ehrlén and Lehtilä 2002). Additionally, even within woody plants, growth rates can be age-dependent, especially at older ages with, for example, xylogenesis (i.e. cambial growth) of conifers slowing down with age (Rossi et al. 2008). While cnidarians such as Hydra scarcely show senescence (Martínez 1998), others do senesce (Hughes 1987, Elahi and Edmunds 2007), indicating possible differences in ageing processes and corresponding rates even in these taxa.

\section{Conclusion}

Phenotypic plasticity can affect the longevity of both plants and animals. Yet, plants and modular animals appear to be much better equipped with plasticity mechanisms than animals, and this is probably what confers greater longevity on them compared to unitary animals (Lanner 2002). However, longevity and senescence in plants and other modular organisms have barely begun to be investigated (Monaghan et al. 2008), and the field is clearly wide open for serious comparative work.

In the given impending scenario of climate change, it also appears that longevity is an important factor that can buffer plants and animals against environmental variability (Morris et al. 2008). Populations of perennial plants and longer-lived animals such as birds and ungulates were found to be less strongly influenced by variations in population growth rate compared to those of annual plants, insects and algae (Morris et al. 2008). It is possible, therefore, that in the future only millenarians will live long enough to tell the tale.

\section{References}

Becker P, Meinzer F C and Wullschleger S D 2000 Hydraulic limitation of tree height: a critique; Func. Ecol. 14 4-11

Borges R M 2008 Plasticity comparisons between plants and animals: concepts and mechanisms; Plant Signal. Behav. 3 367-375

Borges R M 2005 Do plants and animals differ in phenotypic plasticity?; J. Biosci. $3041-50$

Bosch T C G 2007 Why polyps regenerate and we don't: towards a cellular and molecular framework for Hydra regeneration; Dev. Biol. 303 421-433

Bosch T C G 2008 The path less explored: innate immune reactions in cnidarians; in Innate immunity of plants, animals, and humans (ed.) H Heine (Berlin: Springer-Verlag) pp 27-42

Bosch T C G and David C N 1987 Stem cells of Hydra magnipapillata can differentiate into somatic cells and germ cell lines; Dev. Biol. 121 182-191
Bradford G B, Williams B, Rossi R and Bertoncello I 1997 Quiescence cycling, and turnover in the primitive hematopoietic stem cell compartment; Exp. Hematol. 25 445-453

Brown J S and Venable D L 1986 Evolutionary ecology of seedbank annuals in temporally varying environments; Am. Nat. 127 $31-47$

Campisi J 2001 From cells to organisms: can we learn about aging from cells in culture?; Exp. Gerontol. 36 607-618

Chambers J Q, Higuchi N and Schimpel J P 1998 Ancient trees in Amazonia; Nature (London) 391 135-136

Charlesworth B 1980 Evolution in age-structured populations (London: Cambridge University Press)

Cosme-Blanco W and Chang S 2008 Dual role of telomere dysfunction in initiation and suppression of tumorigenesis; Exp. Cell Res. 314 1973-1979

de Magalhães J P, Costa J and Church G M 2007 An analysis of the relationship between metabolism, developmental schedules, and longevity using phylogenetic independent contrasts; $J$. Gerontol. A Biol. Sci. Med. Sci. 62 149-160

Doncaster C P 2003 Evolution of indefinite generation lengths; Biol. J. Linn. Soc. 80 269-280

Ehrlén J and Lehtilä K 2002 How perennial are perennial plants?; Oikos 98 308-322

Elahi R and Edmunds P J 2007 Tissue age affects calcification in the scleractinian coral Madracis mirabilis; Biol. Bull. 212 $20-28$

Enquist B J, Tiffney B H and Niklas K J 2007 Metabolic scaling and the evolutionary dynamics of plant size, form, and diversity: toward a synthesis of ecology, evolution, and paleontology; Int. J. Plant Sci. 168 729-749

Finch C E and Austad S N 2001 History and prospects: symposium on organisms with slow aging; Exp. Gerontol. 36 593-597

Flanary B E and Kletetschka G 2005 Analysis of telomere length and telomerase activity in tree species of various life-spans, and with age in the bristlecone pine Pinus longaeva; Biogerontology 6 101-111

Ford E D and Ishii H 2001 The method of synthesis in ecology; Oikos 93 153-160

Fukuda H 1994 Redifferentiation of single mesophyll cells into tracheary elements; Int. J. Plant Sci. 155 262-271

Haldane J B S 1941 New paths in genetics (London: Allen and Unwin)

Harman D 1956 Aging: a theory based on free radical and radiation chemistry; J. Gerontol. 11 298-300

Haussmann M F, Winkler D W, O'Reilly K M, Huntington C E, Nisbet I C T and Vleck C M 2003 Telomeres shorten more slowly in long-lived birds and mammals than in short-lived ones; Proc. R. Soc. London B 270 1387-1392

Hawkins S and Boudet A 1996 Wound-induced lignin and suberin deposition in a woody angiosperm (Eucalyptus gunnii Hook.): Histochemistry of early changes in young plants; Protoplasma 191 96-104

Hayflick L and Moorehead P S 1961 The serial cultivation of human diploid cell strains; Exp. Cell Res. 25 585-621

Hughes R G 1987 The loss of hydranths of Laomedea flexuosa Alder and other hydroids, with reference to hydroid senescence; in Modern trends in the systematics, ecology, and evolution of hydroids and hydromedusae (eds) J Bouillon, F Boero, F 
Cicogna and P F S Cornelius (Oxford: Clarendon Press) pp 171-184

Hulbert A J, Pamplona R, Buffenstein R and Buttemer W A 2007 Life and death: metabolic rate, membrane composition, and life span of animals; Physiol. Rev. 87 1175-1213

Ishii H and Ford E D 2001 The role of epicormic shoot production in maintaining foliage in old Pseudotsuga menziesii (Douglasfir) trees; Can. J. Bot. 79 251-264

Jackson J B C and Coates A G 1986 Life cycles and evolution of clonal (modular) animals; Philos. Trans. R. Soc. London B 313 $7-22$

Keeley J E and Bond W J 1999 Mast flowering and semelparity in bamboos: the bamboo fire cycle hypothesis; Am. Nat. 154 383-391

Kirkwood T B L 2005 Understanding the odd science of aging; Cell $120437-447$

Kirkwood T B L 1977 Evolution of ageing; Nature (London) 270 301-304.

Kirkwood T B L and Austad S N 2000 Why do we age?; Nature (London) 408 233-238

Kleiber M 1961 The fire of life: an introduction to animal energetics (New York: John Wiley and Sons)

Lanner R M 2002 Why do trees live so long?; Ageing Rev. Res. 1 653-671

Lanner R M and Connor K F 2001 Does bristlecone pine senesce?; Exp. Gerontol. 36 675-685

Liang Y and Van Zant G 2008 Aging stem cells, latexin, and longevity; Exp. Cell Res. 314 1962-1972

Lu T and Finkel T 2008 Free radicals and senescence; Exp. Cell Res. 314 1918-1922

Lynch A J J, Barnes R W, Cambecèdes J and Vaillancourt R E 1998 Genetic evidence that Lomatia tasmanica (Proteaceae) is an ancient clone; Austr. J. Bot. 46 25-33

Martínez D E 1998 Mortality patterns suggest lack of senescence in Hydra; Exp. Gerontol. 33 217-225

Medawar P B 1952 An unsolved problem in biology (London: H K Lewis)

Mocchegiani E, Giacconi R, Muti E, Cipriano C, Costarelli L, Tesei S, Gasparini N and Malavolta M 2007 Zinc-bound metallothioneins and immune plasticity: lessons from very old mice and humans; Immun. Ageing 47 doi: 10.1186/1742-4933-4-7

Monaghan P, Charmantier A, Nussey D H and Ricklefs R E 2008 The evolutionary ecology of senescence; Func. Ecol. 22 371-378

Moore K A and Lemischka I R 2006 Stem cells and their niches; Science 311 1880-1885

Morris W F, Pfister C A, Tuljapurkar S, Haridas C V, Boggs C L, Boyce M S, Bruna E M, Church D R, Coulson T, Doak D F, Forsyth S, Gaillard J-M, Horvitz C C, Kalisz S, Kendall B E, Knight T M, Lee C T and Menges E S 2008 Longevity can buffer plant and animal populations against changing climatic variability; Ecology 89 19-25

Munné-Bosch S 2008 Do perennials really senesce?; Trends Plant Sci. 13 216-220

Munné-Bosch S 2007 Aging in perennials; Crit. Rev. Plant Sci. 26 123-38.

Munné-Bosch S, Jubany-Marí T, and Alegre L 2001 Droughtinduced senescence is characterized by a loss of antioxidant defences in chloroplasts; Plant Cell Environ. 24 1319-1327
Nicolini E, Caraglio Y, Pelissier R, Leroy C and Roggy J C 2003 Epicormic branches: a growth indicator for the tropical forest tree, Dicorynia guianensis Amshoff (Caesalpiniaceae); Ann. Bot. 92 97-105

Niklas K J 1994 Plant allometry. The scaling of form and process (Chicago: University of Chicago Press)

Noodén L, Guiamet J and John I 1997 Senescence mechanisms; Physiol. Plant. 101 746-753

Noodén L and Leopold A C 1988 Senescence and aging in plants (San Diego: Academic Press)

Orians C 2005 Herbivores, vascular pathways, and systemic induction: facts and artifacts; J. Chem. Ecol. 31 2231-2242

Paciorek C J, Condit R, Hubbell S P and Foster R B 2000 The demographics of resprouting in tree and shrub species of a moist tropical forest; J. Ecol. $88765-777$

Partridge L and Gems D 2002 The evolution of longevity; Curr. Biol. 12 R544-546

Passos J F, von Zglinicki T and Kirkwood T B L 2007 Mitochondria and ageing: winning and losing in the numbers game; BioEssays 29 908-917

Peters R H 1983 The ecological implications of body size (Cambridge: Cambridge University Press)

Powell J and Caccone A 2006 Giant tortoises; Curr. Biol. 16 R144-145

Ricklefs R E 2008 The evolution of senescence from a comparative perspective; Func. Ecol. 22 379-392

Rohde A and Bhalerao R P 2007 Plant dormancy in the perennial context; Trends Plant Sci. 12 217-223

Roobrouck V D, Ulloa-Montoya F and Verfaillie C M 2008 Selfrenewal and differentiation capacity of young and aged stem cells; Exp. Cell Res. 314 1937-1944

Rossi S, Deslauriers A, Anfodillo T and Carrer M 2008 Agedependent xylogenesis in timberline conifers; New Phytol. 177 199-208

Rottenberg H 2007a Exceptional longevity in songbirds is associated with high rates of evolution of cytochrome $b$, suggesting selection for reduced generation of free radicals; J. Exp. Biol. 210 2170-2180

Rottenberg H 2007b Coevolution of exceptional longevity, exceptionally high metabolic rates, and mitochondrial DNAcoded proteins in mammals; Exp. Gerontol. 42 364-373

Salomonson A 1996 Interactions between somatic mutations and plant development; Vegetatio 127 71-75

Sebens K P 1983 Population-dynamics and habitat suitability of the intertidal sea-anemones Anthopleura elegantissima and Anthopleura xanthogrammica; Ecol. Monogr. 53 405-433

Sedivy J M, Banumathy G and Adams P D 2008 Aging by epigenetics - A consequence of chromatin damage?; Exp. Cell Res. 314 1909-1917

Seymour R M and Doncaster C P 2007 Density dependence triggers runaway selection of reduced senescence; PLoS Comp. Biol. 3 e256 doi:10.1371/journal.pcbi.0030256

Smith G 2004 Evolution of salmon life histories; Evolution 58 $1634-1636$

Thomas H 2003 Do green plants age, and if so, how?; Topics Curr. Genet. 3 145-171

Venable D L and Brown J S 1988 The selective interactions of dispersal, dormancy and seed size as adaptations for reducing risk in variable environments; Am. Nat. 131 360-384 
Watkinson A 1992 Plant senescence; Trends Ecol. Evol. 7 417-420

Watkinson A R and White J 1985 Some life-history consequences of modular construction in plants; Philos. Trans. R. Soc. London B 313 31-51

Williams G C 1957 Pleiotropy, natural selection and the evolution of senescence; Evolution 11 398-411

Williamson G B, van Eldik T, Delamônica P and Laurance W F 1999 How many millenarians in Amazonia? Sizing the ages of large trees; Trends Plant Sci. 4387
Wright W E, Piatyszek M A, Rainey W E, Byrd W and Shay J W 1996 Telomerase activity in human germline and embryonic tissues and cells; Dev. Genet. 18 173-179

Wright W E and Shay J W 2000 Telomere dynamics in cancer progression and prevention: fundamental differences in human and mouse telomere biology; Nat. Med. 6 849-851

Xiao S, Wang W and Yang X 2008 Evolution of resistance genes in plants; in Innate immunity of plants, animals, and humans (ed.) H Heine (Berlin: Springer-Verlag) pp 1-25

ePublication: 9 December 2008 